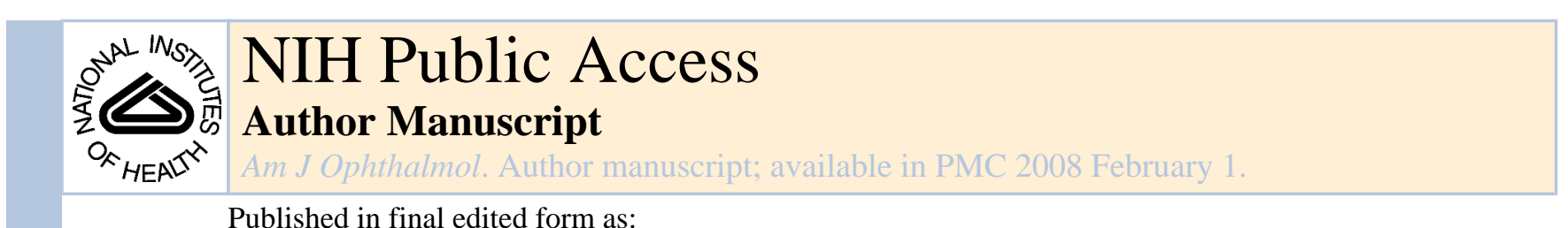

Published in final edited form as:

Am J Ophthalmol. 2007 February ; 143(2): 373.

\title{
Response to Correspondence
}

\author{
Michael X. Repka, MD ${ }^{1}$, Nitza Goldenberg-Cohen, MD¹, and Allison R. Edwards, $\mathbf{M S}^{2}$ \\ 1 Johns Hopkins University School of Medicine, Baltimore, MD
}

2 Jaeb Center for Health Research, Tampa, FL

In the introduction of our paper on peripapillary retinal nerve fiber layer (RNFL) thickness in amblyopic patients we stated, "The purpose of this pilot study was to examine the feasibility of OCT testing in amblyopic children, to provide some pilot data on amblyopic eyes, and assess test-retest variability in this patient population." ${ }^{1} \mathrm{We}$ included patients with a mean age of 11.2 years with a single patient over 20 years of age ( 28 years old) as our eligibility criterion for the study was up to 30 years. The inclusion of this amblyopic patient would not appreciably affect our assessment of the feasibility of OCT testing in amblyopic eyes, and is consistent with the other purposes of our study.

\section{Acknowledgements}

We thank the authors for alerting us to their work in 14 patients with strabismic amblyopia 5 to 18 years of age with a mean of 10.4 years. ${ }^{2}$ Our findings were similar to theirs with no difference between the peripapillary RNFL thickness of sound and amblyopic eyes.

\section{References}

1. Repka MX, Goldenberg-Cohen N, Edwards AR. Retinal nerve fiber layer thickness in amblyopic eyes. Am J Ophthalmol 2006;142:247-51. [PubMed: 16876504]

2. Altintas, O.; Yüksel, N.; Özkan, B.; Çaglar, Y. Journal of Pediatric Ophthalmology and Strabismus. 2005. Thickness of the Retinal Nerve Fiber Layer, Macular Thickness, and Macular Volume in Patients with Strabismic Amblyopia; p. 2126-221.

Corresponding author: Michael X. Repka, MD, Wilmer 233, Johns Hopkins Hospital, 600 North Wolfe Street, Baltimore, MD, USA 21287-9028,mrepka@jhmi.edu.

Publisher's Disclaimer: This is a PDF file of an unedited manuscript that has been accepted for publication. As a service to our customers we are providing this early version of the manuscript. The manuscript will undergo copyediting, typesetting, and review of the resulting proof before it is published in its final citable form. Please note that during the production process errors may be discovered which could affect the content, and all legal disclaimers that apply to the journal pertain. 